Research Article

\title{
Seismic Response and Safety Assessment of an Existing Concrete Chimney under Wind Load
}

\author{
Xuansheng Cheng $\left(\mathbb{D},{ }^{1}\right.$ Hongjie Qian, ${ }^{1}$ Chao Wang, ${ }^{2}$ and Xuedong Fu ${ }^{2}$ \\ ${ }^{1}$ Key Laboratory of Disaster Prevention and Mitigation in Civil Engineering of Gansu Province, \\ Lanzhou University of Technology, Lanzhou 730050, China \\ ${ }^{2}$ Western Engineering Research Center of Disaster Mitigation in Civil Engineering of Ministry of Education, \\ Lanzhou University of Technology, Lanzhou 730050, China \\ Correspondence should be addressed to Xuansheng Cheng; chengxuansheng@gmail.com
}

Received 10 July 2018; Revised 9 October 2018; Accepted 6 November 2018; Published 2 December 2018

Academic Editor: Mickaël Lallart

Copyright ( 2018 Xuansheng Cheng et al. This is an open access article distributed under the Creative Commons Attribution License, which permits unrestricted use, distribution, and reproduction in any medium, provided the original work is properly cited.

\begin{abstract}
A safety assessment of a chimney under the action of wind and earthquake is performed on one of the reinforced concrete chimneys in the Jinchuan company in China. The assessment is based on the linear filtering method, and wind loads of several heights on one field are simulated by MATLAB. The displacement of the structure under the action of wind load and earthquake is analyzed using maximum value superposition, and the stress on the chimney is calculated in four cases using the equal curvature criterion method. The time-history responses of the tall chimney structure under linear and nonlinear elastic conditions are discussed. The results show that for a chimney under wind load or frequent earthquakes, the displacement limit can meet the code requirements; however, under the combined action of frequent earthquakes and wind load, the structural displacement is bigger than other conditions. When the chimney is acted upon by a wind load, frequent earthquake action, or the combined action of wind load and frequent earthquake action, the maximum compressive stress, maximum tensile stress, and maximum shear stress are concentrated at the bottom of the chimney. The ultimate bearing capacity of a reinforced concrete chimney under three conditions can meet the original design requirements, but the maximum compressive stress at the bottom approaches the designed tensile limit value under the action of rare earthquakes; under these conditions, the bottom of the chimney may experience partial damage.
\end{abstract}

\section{Introduction}

Reinforced concrete (RC) chimneys are an indispensable structure in industrial buildings, and their structural safety directly determines the safety of surrounding buildings and people. Earthquakes and wind are the main factors to consider in the design of RC chimneys. The earthquake dynamic responses of chimneys are different from those of general high-rise buildings, as they are irregular and unpredictable. Seismic action is the primary factor in chimney design. With increasing height, the dynamic response under earthquakes and wind becomes more intense and often causes fatal damage. Therefore, determining the dynamic response and assessing the safety of an RC chimney under wind and earthquakes is an urgent task.

Significant research has been carried out regarding the dynamic response and safety evaluation of RC chimneys under earthquakes and wind. Liu and He [1] analyzed the response of chimneys under the combined action of horizontal and vertical earthquake motion. Pan et al. [2-4] drew the conclusion that the bending moment and shear of highrise structures obviously increased under the combined action of bidirectional seismic waves. Liu et al. [5] determined that the vertical seismic response of a high-rise structure had obvious regularity. Chen and Ren [6] carried out a simulation analysis of an RC chimney with engineering examples. Liu et al. [7] performed calculations and an analysis of the transient responses of earthquakes on tall chimney structures based on HHT transform and harmonic earthquake response theory. Shiau and Yang [8] proposed applying the vibration mode decomposition response spectrum method to the structure of concrete chimneys. Wilson $[9,10]$ concluded that the RC chimney possessed some ductility, and the seismic response induced by high 
modes was significant under complicated earthquakes with long periods. Li et al. [11] obtained actual data by measuring Taipei Building 101 and compared these data with dynamic characteristic data. Feng et al. [12] conducted an analysis of the wind-induced response on three typical high-rise buildings by wind tunnel tests and the random vibration theory method. $\mathrm{Li}$ and $\mathrm{Lu}$ [13] simulated the fluctuating wind pressure time-history of chimneys of various heights. $\mathrm{Li}$ and $\mathrm{Li}[14]$ proposed an overall optimization method combined with wind tunnel testing and the finite element method (FEM). Minghini et al. [15] proposed an accurate finite element model built by incorporating suitable tension and compression. Yang et al. [16] studied the reliability of chimney structures under the current standards requirements for long-term wind action, corrosion, hot action, lower-level construction, and lower design standards. Altunisik [17] presents a comparison of the earthquake behavior of RC minarets using fiber-reinforced polymer (FRP) composite. Karaca et al. [18] carried out the dynamic responses of chimneys after FRP strengthening. Zhou et al. [19] revealed that the RC chimney structure had considerable ductility and could withstand a strong earthquake with some structural damage using fragility analysis. Gorski [20] investigated the influence of the three components mentioned above on the total cross-wind response of the chimney. Iban et al. [21] developed a numerical technique for fluid-structure interaction. Cohen et al. [22] studied the seismic vulnerability of an elevated steel tank within a reinforced concrete chimney. Bońkowski et al. [23] analyzed the time-history response of a slender tower under translational-rocking seismic excitation.

In summary, the current research is mainly focused on the design and theoretical analysis of chimneys, and only seismic action or wind load is analyzed. There are no relevant reports on the dynamic response and safety evaluation of existing concrete chimneys under earthquakes and wind loads. Therefore, in this paper, the dynamic response of existing concrete chimneys under earthquakes and wind load is analyzed, and the safety performance of a chimney is evaluated.

\section{Wind Vibration Response}

For tall structures, the horizontal component of wind can make the structure vibrate in all directions, and the vertical component affects only the axial force of the structure itself. It can be seen that the horizontal component of wind significantly influences the structure. Therefore, this paper analyzes the dynamic response of the horizontal component of wind.

For any height under the action of wind, there will be forces in several directions on the structural surface. To more intuitively and effectively express the effect of wind speed on the structure, wind speed is usually transformed into wind pressure, and surface wind pressure is divided along the surface into the three forces: downward wind force, permanent wind force, and torsional moment. The three forces have the following effects on the structure:

(1) The forces along the wind direction include mean wind and fluctuating wind. As a random variable vector, fluctuating wind will cause the vibration of the structure along the wind direction.

(2) The horizontal wind can cause the structure itself to resonate. However, due to the wind vortex, the forces on the structure vary and are related to both the structure and the Reynolds number.

(3) When the wind causes the eccentric torque of the structure, the structure will experience torsional vibration. If the structure itself cannot be restored after vibration, the structure will be unstable. The downward wind force usually causes structural vibration along the wind direction. For a relatively symmetrical structure, although the vortexes caused by the lateral effect exist in asymmetric forms while wind torque exists, the impact of vortexes is very small. Thus, wind torque is generally considered when the structure is complex and asymmetrical. Therefore, the chimney studied in this paper is used to study only the wind load response in the direction of the wind.

For tall structures [24], vibrations in all directions occur due to the horizontal component of wind, and the axial force of the structure itself is affected by the vertical component. Thus, dynamic response analysis is carried out for the horizontal component of wind.

Wind fluctuations are simulated using the linear filtering method [25], and the wind velocity time-history curve is obtained by MATLAB. The Kaimal spectrum is selected as the power spectral density function as follows:

$$
\frac{n S(f)}{u_{*}^{2}}=\frac{200 f}{(1+50 f)^{5 / 3}},
$$

where $S(f)$ is the power spectrum density of the Kaimal spectrum, $n$ is the frequency, $u_{*}$ is the frictional velocity, $f=$ $n z / \bar{U}(z)$ is a dimensionless coordinate, $\bar{U}(z)$ is the mean wind velocity, and $z$ is the structure height. After significant checking and testing, the average wind speed fits the formula $\bar{U}(z)=(1 / k) u_{*} \ln \left(z / z_{0}\right)$. In this formula, $k=0.4$, where $k$ is known as the Kaman constant, and $z_{0}$ is the surface roughness.

When multidimensional wind speed time-history is simulated by the linear filtering method, the $M$ related random wind processes are written as

$$
u(t)=\left[u^{1}(t), \ldots, u^{i}(t), \ldots, u^{M}(t)\right]^{T},
$$

$u(t)$ is calculated as

$$
u(t)=\sum_{k=1}^{p} \psi_{k} u(t-k \Delta t)+N(t) .
$$

The mean value of $N^{i}(t)$ is $0 . N^{i}(t)$ follows a normal distribution random process with a given covariance, $i=1, \ldots, M . \psi_{k}$ is the regression coefficient matrix.

According to equation (3), the simulation of wind speed time-history is the solution of $\psi_{k}$ and $N(t)$.

2.1. Solution of $\psi_{k}$. According to random vibration theory, the relationship between the power spectrum density and the 
correlation function follows the Wiener-Khinchin formula, that is,

$$
\begin{array}{r}
R_{u}^{i k}(j \Delta t)=\int_{0}^{\infty} S_{u}^{i k}(n) \cos (2 \pi j \Delta t) d n, \\
(i, k=1, \ldots, M),
\end{array}
$$

where $S_{u}^{i k}(n)$ is the cross-power spectrum density between points $u^{i}(t)$.

One space point $i(i=1, \ldots, M)$ with covariances of $u^{i}(t)$ and $u^{i}(t-k \Delta t)$ can be expressed as

$$
\begin{aligned}
R_{u}^{i} & {[k \Delta t] } \\
& =E\left[\left\{u^{i}(t-k \Delta t)-E\left[u^{i}(t-k \Delta t)\right]\right\}\left\{u^{i}(t)-E\left[u^{i}(t)\right]\right\}\right] .
\end{aligned}
$$

Because $u^{i}(t)$ and $u^{i}(t-k \Delta t)$ follow the stationary random wind process with a mean value of 0 and covariance is a function of time difference only, equation (3) can be rewritten as

$$
R_{u}^{i}[k \Delta t]=E\left[u^{i}(t-k \Delta t) u^{i}(t)\right]
$$

Both sides of equation (3) are multiplied by $[u(t-$ $k \Delta t)]=\left[u^{1}(t-k \Delta t), \ldots, u^{i}(t-k \Delta t), \ldots, u^{M}(t-k \Delta t)\right]$, and the mean value of both sides is calculated. Considering that the mean value of $N^{i}(t)$ is 0 , the relationship between covariance and the regression coefficient can be expressed as

$$
\mathbf{R}=\overline{\mathbf{R}} \cdot \psi_{k},
$$

where

$$
\begin{aligned}
& \mathbf{R}=\left[R_{u}(\Delta t), \ldots, R_{u}(p \Delta t)\right]^{T}, \\
& \psi_{k}=\left[\psi_{1}^{T}, \ldots, \psi_{p}^{T}\right]^{T} \text {, } \\
& \overline{\mathbf{R}}_{p M \times M}=\left[\begin{array}{ccccc}
R_{u}(0) & R_{u}(t) & \cdots & R_{u}[(p-2) \Delta t] & R_{u}[(p-1) \Delta t] \\
R_{u}(\Delta t) & R_{u}(2 \Delta t) & \cdots & R_{u}[(p-1) \Delta t] & R_{u}(0) \\
\vdots & \vdots & \ddots & \vdots & \vdots \\
R_{u}[(p-2) \Delta t] & R_{u}[(p-1) \Delta t] & \cdots & R_{u}[(p-4) \Delta t] & R_{u}[(p-3) \Delta t] \\
R_{u}[(p-1) \Delta t] & R_{u}(0) & \cdots & R_{u}[(p-3) \Delta t] & R_{u}[(p-2) \Delta t]
\end{array}\right], \\
& \mathbf{R}_{u}(j \Delta t)_{M \times M}=\left[\begin{array}{ccc}
R_{u}^{11}(j \Delta t) & \cdots & R_{u}^{1 M}(j \Delta t) \\
\vdots & \ddots & \vdots \\
R_{u}^{M 1}(j \Delta t) & \cdots & R_{u}^{M M}(j \Delta t)
\end{array}\right] \text {, } \\
& \psi_{j M \times M}=\left[\begin{array}{ccc}
\psi_{j}^{11} & \cdots & \psi_{j}^{1 M} \\
\vdots & \ddots & \vdots \\
\psi_{j}^{M 1} & \cdots & \psi_{j}^{M M}
\end{array}\right], \quad(j=1, \ldots, p) \text {. }
\end{aligned}
$$

The regression coefficient matrix $\psi_{k}$ can be obtained by solving the linear equation group given by equation (7).

2.2. Solution of $N(t)$. Both sides of equation (7) are multiplied by $u(t)=\left[u^{1}(t), \ldots, u^{i}(t), \ldots, u^{M}(t)\right]$, that is,

$$
\mathbf{R}_{N}=\mathbf{R}_{u}(0)-\sum_{k=1}^{p} \mathbf{R}_{u}(k \Delta t) .
$$

According to equation (9), $\mathbf{R}_{N}$ is obtained and analyzed by the Cholesky method, that is,

$$
\left\{\begin{array}{l}
\mathbf{R}_{N}=\mathbf{L} \cdot \mathbf{L}^{T}, \\
N(t)=\mathbf{L} \cdot n(t),
\end{array}\right.
$$

where $n(t)=\left[n^{1}(t), \ldots, n^{i}(t), \ldots, n^{M}(t)\right]^{T} . n(t)$ consists of $M$ independent random vectors, which has a mean value of zero and unit variance.

2.3. Generation of Random Wind Speed Time-History. The discretization of equation (9) by a time interval $\Delta t$ is carried out with $\psi_{k}$ and $N(t)$. Therefore, we can get a discrete fluctuating wind velocity time-history vector with $M$ spatial correlation time interval $\Delta t$.

\section{Earthquake Response}

The modal analysis [26] of the chimney is performed by combining the vibration superposition method [27] and FEM with the lowest mass participation factor and some design requirements.

The dynamic equilibrium equation of the structural system can be expressed as a group of two-order differential equations $N_{d}$ :

$$
\mathbf{M u}(t)+\mathbf{C} \dot{\mathbf{u}}(t)+\mathbf{K u}(t)=\mathbf{F}(t)=\sum_{j=1}^{J} \mathbf{f}_{j} g_{j}(t),
$$

where $\mathbf{f}_{j}$ represents the space vector, which is unrelated to time and $g_{j}(t)$ represents the $j$-th function related to time.

According to the separation variable method and assuming that the value of equation (11) can be expressed as 


$$
\mathbf{u}(t)=\Phi \mathbf{Y}(t)
$$

where $\Phi$ is a $N_{d} \times N$ matrix, including the spatial vector of $N$ nontime function, $\mathbf{Y}(t)$ can be expressed as a vector containing $N$ time function.

Taking the derivative to equation (12), there is

$$
\begin{aligned}
\dot{\mathbf{u}}(t) & =\Phi \dot{\mathbf{Y}}(t), \\
\ddot{\mathbf{u}}(t) & =\Phi \ddot{\mathbf{Y}}(t) .
\end{aligned}
$$

According to the stiffness and quality of the orthogonal condition, there is

$$
\begin{aligned}
& \boldsymbol{\Phi}^{T} \mathbf{M} \boldsymbol{\Phi}=\mathbf{I}, \\
& \boldsymbol{\Phi}^{T} \mathbf{K} \boldsymbol{\Phi}=\mathbf{\Omega}^{2},
\end{aligned}
$$

where $\Omega^{2}$ is a diagonal matrix with a diagonal term of $\omega_{n}^{2}$ and I is a unit diagonal matrix.

Substituting equation (11) into equations (12)-(14), there is

$$
\mathbf{I Y}(t) \mathbf{d} \dot{\mathbf{Y}}(t)+\mathbf{\Omega}^{2} \mathbf{Y}(t)=\sum_{j=1}^{J} p_{j} g_{j}(t),
$$

where $p_{j}=\boldsymbol{\Phi}^{T} \mathbf{f}\left(p_{j}\right.$ is the modal participation coefficient of load function $j$ ) and $\mathbf{d}$ is the damping matrix. To obtain the solution, $d_{m}=2 \xi_{n} \omega_{n}$ is defined as the diagonal terms of modal damping, that is,

$$
\dot{\mathbf{y}}_{n}(t)+2 \xi_{n} \omega_{n} \dot{y}(t)+\omega_{n}^{2} y(t)=\sum_{j=1}^{J} p_{n j} g_{j}(t)
$$

\section{Safety Assessment}

4.1. Engineering Situation. The height of the RC chimney used to manufacture nickel carbonyl is $75 \mathrm{~m}$. The concrete strength is $35 \mathrm{MPa}$. The bottom diameter is $5.904 \mathrm{~m}$, and the top diameter is $2.082 \mathrm{~m}$. The bottom of the chimney outer lining is concrete with a thickness of $250 \mathrm{~mm}$, and the lining is a brick masonry insulation layer which has a thickness of $300 \mathrm{~mm}$. Partial cracking occurred at the top of the chimney, but the other sections were in good condition. Thus, the effect of temperature on the structure can be excluded. The vertical and local cracks are shown in Figure 1.

There are local fractures and horizontal cracks at the top of the chimney, and significant anomalies were not found in the other sections. Additionally, vertical cracks in the surface were not found. The cause of the fractures may be the action of earthquake or wind load or the combined action of earthquake and wind load.

\subsection{Analysis of the Linear Elastic Calculation Results}

\subsubsection{Displacement Analysis}

(1) Boundary Condition. The chimney structure is only fixed at the bottom, and so the boundary conditions are as follows: the bottom is fixed and the top is free.

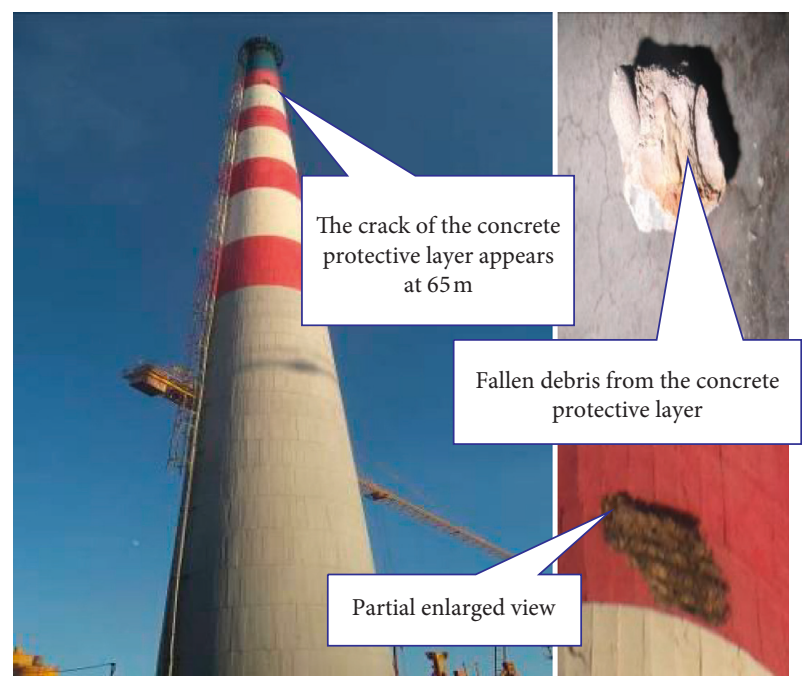

Figure 1: Concrete chimney.

(2) Wind Load Action. The height of the calculation model chimney is $75 \mathrm{~m}$. The concrete strength is $35 \mathrm{MPa}$. A timehistory analysis with an elastic range is performed. The acceleration and displacement time-history curves at $25 \mathrm{~m}$, $50 \mathrm{~m}$, and $75 \mathrm{~m}$ are shown in Figures 2-4, respectively.

From Figures 2 to 4, with the increase of height, the acceleration and the displacement of the chimney obviously increase. The extreme displacement under several heights appears at $74.6 \mathrm{~s}$. For both the acceleration curve and the displacement curve, the response curve of each node in the chimney is similar, but the amplitude is different. The accelerations and displacements of these extreme moments are consistent. The wind pressure acceleration is relatively stable and durative. The amplitude of the displacement response of the chimney under the wind load is obvious along the height, and it can be seen from the above figure that the amplitude of the elongated protrusions at the top of the building increases sharply under the wind load. The vertex displacement is large, which conforms to the characteristics of the flexible structure. Many displacement calculations under wind load appeared in the existing literature. In consideration of the requirement of the displacement limit, the displacement limit value of the RC chimneys of various heights under wind load did not exceed the limit value of $H / 100$. The results show that the increasing displacement amplitudes of the upper part of the chimney are larger than those of the lower part, and the ratio of the displacement extreme value to $\mathrm{H} / 100$ increases with increasing altitude.

(3) Earthquake Response. Considering both frequent earthquakes and rare earthquakes, according to the building seismic design specifications, horizontal earthquake influence coefficients are as shown in Table 1.

The three main points of seismic wave selection are the characteristic and peak of the continuous time spectrum. The El-Centro wave is selected (peak value $294.0 \mathrm{~cm} / \mathrm{s}^{2}$ ), and the sampling period is $0.02 \mathrm{~s}$. The degree of seismic fortification is intensity $8(0.15 \mathrm{~g})$. The damping ratio is $5 \%$. The seismic wave diagram can be seen in Figure 5. The extreme 


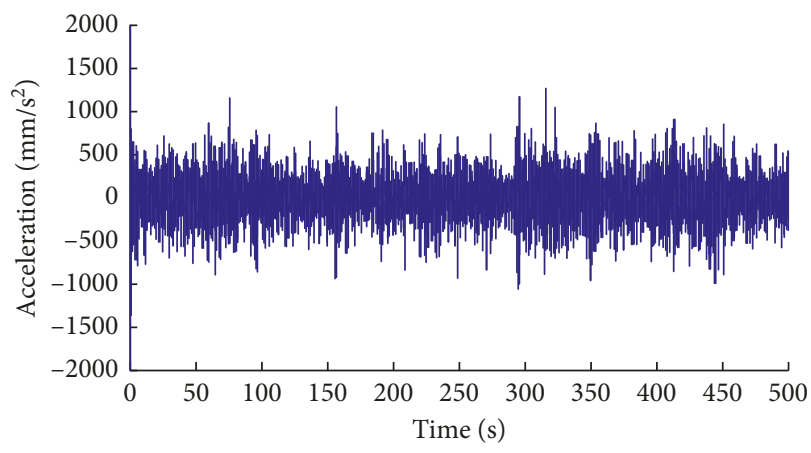

(a)

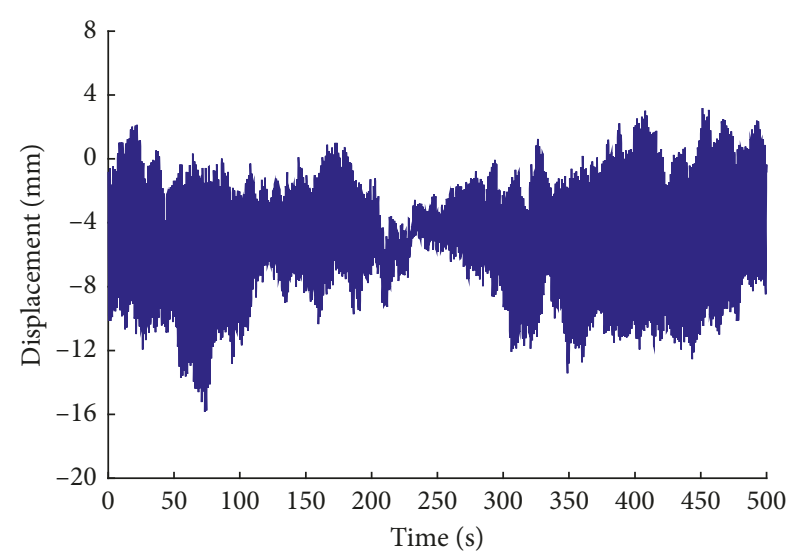

(b)

Figure 2: Time-history curves of acceleration and displacement at $25 \mathrm{~m}$ : (a) acceleration at $25 \mathrm{~m}$; (b) displacement at $25 \mathrm{~m}$.

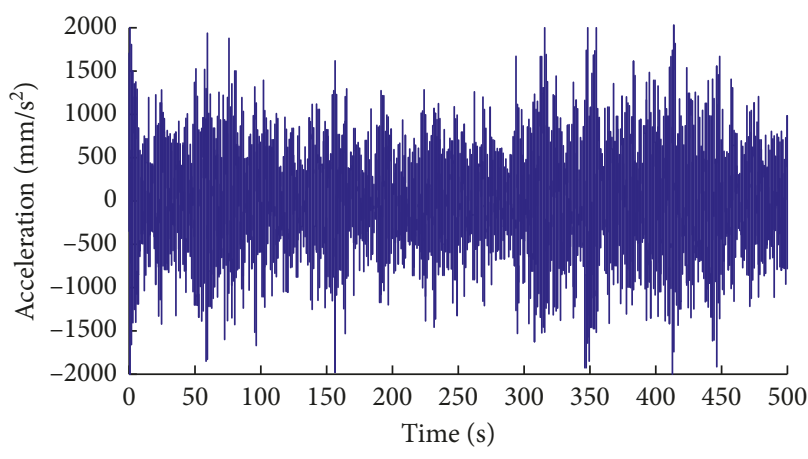

(a)

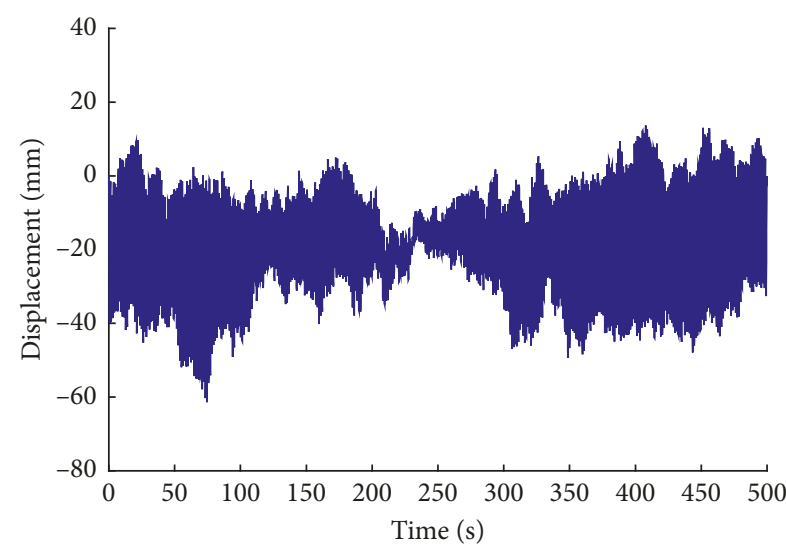

(b)

FIgURe 3: Time-history curves of acceleration and displacement at $50 \mathrm{~m}$ : (a) acceleration at $50 \mathrm{~m}$; (b) displacement at $50 \mathrm{~m}$.

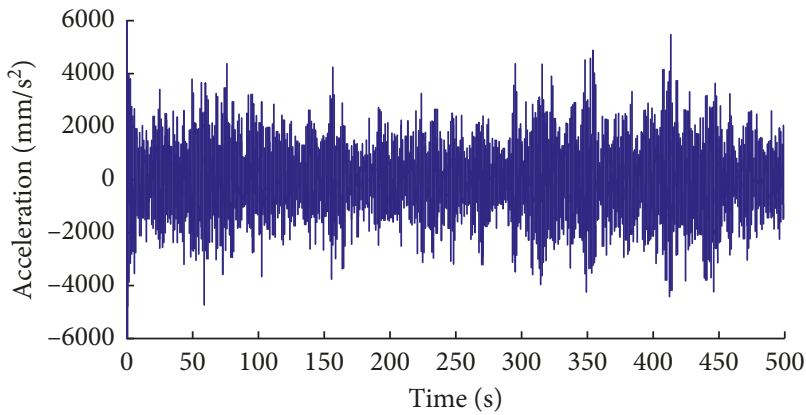

(a)

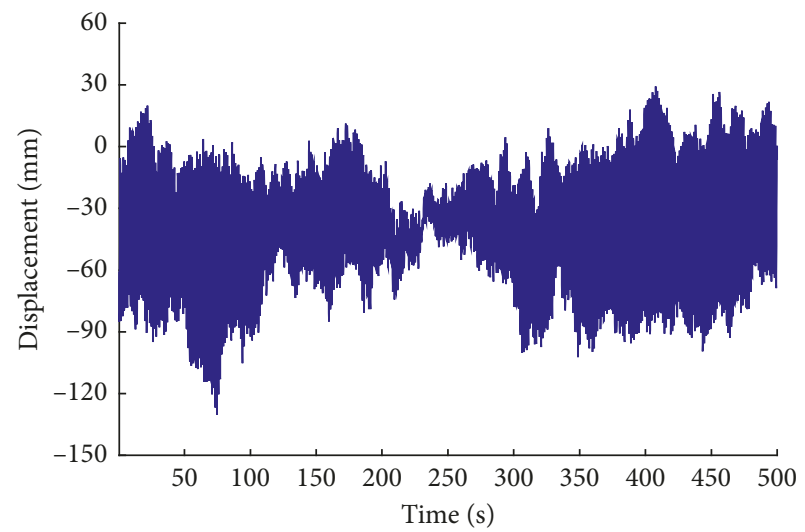

(b)

Figure 4: Time-history curves of acceleration and displacement at $75 \mathrm{~m}$ : (a) acceleration at $75 \mathrm{~m}$; (b) displacement at $75 \mathrm{~m}$.

displacement values of several heights were calculated and can be seen in Table 2. The displacement amplitude during frequent earthquakes and rare earthquakes can be seen in Tables 3 and 4, respectively.
From Table 2 to Table 4, the three moments with extreme values are $5.96 \mathrm{~s}, 6.00 \mathrm{~s}$, and $6.02 \mathrm{~s}$. With the increase of chimney height, the time of displacement extreme value gradually decreases. Moreover, the variation of the 
TABLE 1: Maximum values of horizontal earthquake influence coefficients for several seismic intensities.

\begin{tabular}{lccc}
\hline Earthquake effect & 7 & 8 & 9 \\
\hline Frequent earthquake & $0.08(0.12)$ & $0.16(0.24)$ & 0.32 \\
Rare earthquake & $0.50(0.72)$ & $0.90(1.20)$ & 1.40 \\
\hline
\end{tabular}

Note. The value in brackets is used to design earthquake acceleration from $0.15 \mathrm{~g}$ to $0.30 \mathrm{~g}$.

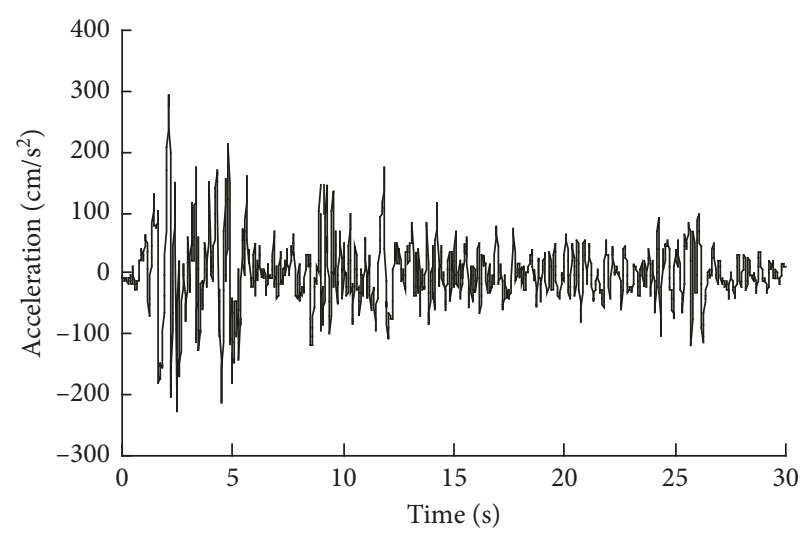

FIgURE 5: El-Centro wave acceleration time-history curve.

TABLE 2: Displacement extreme values at several heights.

\begin{tabular}{lcccc}
\hline & Height $(\mathrm{m})$ & 25 & 50 & 75 \\
\hline $\begin{array}{l}\text { Displacement } \\
\text { extreme }\end{array}$ & $\begin{array}{c}\text { Frequent } \\
\text { earthquake } \\
\text { value }(\mathrm{mm})\end{array}$ & 26.44 & 96.05 & 191.72 \\
$\begin{array}{c}\text { Rare } \\
\text { Time }(\mathrm{s})\end{array}$ & earthquake & 39.55 & 142.38 & 284.76 \\
\hline
\end{tabular}

TABle 3: Displacement amplitudes under frequent earthquake conditions.

\begin{tabular}{lccc}
\hline $\begin{array}{l}\text { Height } \\
(\mathrm{m})\end{array}$ & $\begin{array}{c}\text { Displacement extreme } \\
\text { value }(\mathrm{mm})\end{array}$ & $\begin{array}{c}\text { Displacement limit value } \\
H / 100(\mathrm{~mm})\end{array}$ & Ratio \\
\hline 75 & 168 & 750 & 0.22 \\
70 & 150 & 700 & 0.21 \\
65 & 133 & 650 & 0.20 \\
60 & 116 & 600 & 0.19 \\
55 & 100 & 550 & 0.18 \\
50 & 84 & 500 & 0.17 \\
45 & 70 & 450 & 0.16 \\
40 & 56 & 400 & 0.14 \\
35 & 44 & 350 & 0.13 \\
30 & 33 & 300 & 0.11 \\
25 & 23 & 250 & 0.09 \\
20 & 15 & 200 & 0.08 \\
15 & 8 & 150 & 0.05 \\
10 & 3 & 100 & 0.03 \\
5 & 1 & 50 & 0.02 \\
\hline
\end{tabular}

maximum displacement response of the chimney under earthquakes is obvious. The displacement extreme value of the RC chimney meets the requirements under earthquake action.
TABle 4: Displacement amplitudes under rare earthquake conditions.

\begin{tabular}{lccc}
\hline $\begin{array}{l}\text { Height } \\
(\mathrm{m})\end{array}$ & $\begin{array}{c}\text { Displacement extreme } \\
\text { value }(\mathrm{mm})\end{array}$ & $\begin{array}{c}\text { Displacement limit value } \\
\mathrm{H} / 100(\mathrm{~mm})\end{array}$ & Ratio \\
\hline 75 & 252 & 750 & 0.34 \\
70 & 225 & 700 & 0.32 \\
65 & 200 & 650 & 0.31 \\
60 & 174 & 600 & 0.29 \\
55 & 150 & 550 & 0.27 \\
50 & 126 & 500 & 0.25 \\
45 & 105 & 450 & 0.23 \\
40 & 84 & 400 & 0.21 \\
35 & 66 & 350 & 0.19 \\
30 & 50 & 300 & 0.17 \\
25 & 35 & 250 & 0.14 \\
20 & 23 & 200 & 0.12 \\
15 & 13 & 150 & 0.09 \\
10 & 5 & 100 & 0.05 \\
5 & 2 & 50 & 0.04 \\
\hline
\end{tabular}

(4) The Combined Response to Frequent Earthquakes and Wind Load. The crack of the RC chimney used for the manufacture of nickel carbonyl is mainly caused by the combined action of earthquakes and wind load. Given that the acting time of the wind load is longer than that of the earthquake, the analysis of the combined action of earthquake and wind load is carried out by the method of superimposing the maximum value. The calculation results are shown in Table 5.

From Table 5, the most displacement extreme value of the RC chimney is $533 \mathrm{~mm}$ at $75 \mathrm{~m}$ under the combined action of earthquake and wind load, and the structural displacement does not exceed the specified limit. The extreme displacement value of the middle and upper parts of the chimney also satisfies the displacement limit. According to Table 5, the displacement of the RC chimney under earthquake and wind load action is larger than wind and earthquake action alone.

Given that the extreme displacement value of the middle and upper parts of the chimney under the combined action of frequent earthquakes and wind load did not approach the displacement limit and the probability of suffering rare earthquakes is small, the extreme displacement value will not be calculated under the combined action of rare earthquakes and wind load in this paper.

\subsubsection{Stress Analysis}

(1) Wind Load Action. Basic wind pressure $w_{0}$ equals $0.35 \mathrm{kN} / \mathrm{m}^{2}$. The ground roughness is Grade B. Wind load is one of the main loads that influence flexible high-rise structures, and it is necessary for the design and confirmation of the wind load. The calculation and analysis of wind load can be seen in Tables 6 and 7.

Based on Table 6 , the maximum stress appears at the bottom of various sections, and it meets the design value of the shear bearing capacity. Thus, the ability of the chimney to resist shearing is adequate. From Table 7, the peak value of 
TABLE 5: Displacement amplitudes under wind and earthquake action.

\begin{tabular}{lccc}
\hline $\begin{array}{l}\text { Height } \\
(\mathrm{m})\end{array}$ & $\begin{array}{c}\text { Displacement extreme } \\
\text { value }(\mathrm{mm})\end{array}$ & $\begin{array}{c}\text { Displacement limit value } \\
H / 100(\mathrm{~mm})\end{array}$ & Ratio \\
\hline 75 & 533 & 750 & 0.71 \\
70 & 490 & 700 & 0.70 \\
65 & 449 & 650 & 0.69 \\
60 & 402 & 600 & 0.67 \\
55 & 352 & 550 & 0.64 \\
50 & 310 & 500 & 0.62 \\
45 & 270 & 450 & 0.60 \\
40 & 228 & 400 & 0.57 \\
35 & 186 & 350 & 0.53 \\
30 & 135 & 300 & 0.45 \\
25 & 83 & 250 & 0.33 \\
20 & 48 & 200 & 0.24 \\
15 & 24 & 150 & 0.16 \\
10 & 8 & 100 & 0.08 \\
5 & 1 & 50 & 0.02 \\
\hline
\end{tabular}

TABLE 6: Shear stress under the action of wind.

\begin{tabular}{lcccc}
\hline $\begin{array}{l}\text { Ground } \\
\text { elevation } \\
(\mathrm{m})\end{array}$ & $\begin{array}{c}\text { Standard } \\
\text { value } \\
(\mathrm{kN})\end{array}$ & $\begin{array}{c}\text { Sectional } \\
\text { area } \\
\left(\mathrm{m}^{2}\right)\end{array}$ & $\begin{array}{c}\text { Maximum stress at } \\
\text { the bottom of } \\
\text { different sections } \\
(\mathrm{kPa})\end{array}$ & $\begin{array}{c}\text { Design } \\
\text { value of } \\
\text { bearing } \\
\text { capacity } \\
(\mathrm{kPa})\end{array}$ \\
\hline 70 & 411.41 & 3.952004 & 208.2032 & 1099 \\
65 & 428.03 & 4.112458 & 208.1626 & 1099 \\
60 & 503.28 & 5.635044 & 178.625 & 1099 \\
55 & 580.93 & 5.558742 & 209.0149 & 1099 \\
50 & 602.37 & 5.76504 & 208.9734 & 1099 \\
45 & 623.81 & 5.971338 & 208.9347 & 1099 \\
40 & 626.60 & 6.177636 & 202.8608 & 1099 \\
35 & 693.17 & 7.111786 & 194.9356 & 1099 \\
30 & 780.81 & 7.018528 & 222.4996 & 1099 \\
25 & 807.07 & 7.27067 & 222.0071 & 1099 \\
20 & 1269.68 & 7.522812 & 337.5546 & 1099 \\
10 & 1771.69 & 8.027096 & 441.4274 & 1099 \\
\hline
\end{tabular}

the bending moment is $5893.57 \mathrm{kN} \cdot \mathrm{m}$ under wind load alone, but it is almost half the standard value of the bending moment under earthquake action. Thus, the internal force of the chimney under earthquake action is almost twice that under the wind load, which still meets the design requirements. The maximum compressive stress and the maximum tensile stress are much smaller than the compression and tensile strengths of concrete.

(2) Earthquake Response. The internal force of chimneys with heights of $25 \mathrm{~m}, 50 \mathrm{~m}$, and $75 \mathrm{~m}$ can be seen in Figures 6-8 under the frequent earthquake response at $6.02 \mathrm{~s}$, $6.00 \mathrm{~s}$, and $5.96 \mathrm{~s}$, respectively.

From Figures 6 to 8, the maximum stress zone gradually moves toward the bottom of the chimney as time decreases, and the maximum value decreases when the minimum value increases. The greatest dynamic response of the chimney occurs at the bottom $10 \mathrm{~m}$ and the minimum occurs at the top $10 \mathrm{~m}$. The maximum stress value does not exceed the structural admissible stress range; therefore, the structure meets the stiffness requirements. The stress value of the chimney is calculated by the equal curvature criterion method. The maximum stress value and the maximum shear stress value of the chimney under the action of frequent earthquakes are shown in Tables 8 and 9.

From Table 8, the coefficient of the bending section of the structure is influenced by the height of the chimney, and the maximum value appears at the bottom. As height increases, the coefficient gradually decreases. The maximum compressive stress and the tensile stress both appear at the bottom of the chimney, and the compression stress is greater than the tensile stress at various heights and at the bottom of the chimney. From Table 9, shear standard values change at various sections, and the maximum value occurs at the middle and bottom of different sections. The maximum shear stress also appears at the bottom of the chimney, but with the height change, the numerical variation amplitude is not very large.

Given that the maximum stress at the bottom of various sections is far smaller than the designed value of shear capacity during frequent earthquakes, only the maximum stress values under the action of rare earthquakes will be calculated, as shown in Table 10.

From Table 10, the most disadvantaged position is the bottom of the chimney. The maximum compressive stress at the bottom is $1865.22 \mathrm{kPa}$, and maximum tensile stress is $1607.95 \mathrm{kPa}$. The maximum compressive stress at the bottom approaches the limit tensile design value, which shows that the chimney may experience partial damage at its bottom during rare earthquakes.

(3) Combined Response to Earthquake and Wind Load. Given that the probability of suffering rare earthquakes is small, the maximum stress will not be calculated under the combined action of rare earthquakes and wind load. The combined values of frequent earthquake action and wind load are shown in Table 11.

From Table 11, the most disadvantaged position of the chimney is the bottom. The maximum compressive stress at the bottom is $3569.22 \mathrm{kPa}$, and maximum tensile stress is $695.1634 \mathrm{kPa}$. The stress under the combined response to earthquake and wind load is significantly larger than the responses to either wind load or earthquake action alone. The maximum bearing capacity occurs at the structure bottom under the combined response to earthquake and wind load, and the ultimate bearing capacity of the RC chimney meets the requirements under the combined action.

4.3. Analysis of the Nonlinear Elastic Calculation Results. When considering materials' nonlinearity and $P-\Delta$ effect, the displacement and acceleration amplitudes under the action of wind load, earthquake, or wind and earthquake are shown in Table 12.

From Table 12, with nonlinear analysis, the displacement and acceleration amplitudes under wind load are less than earthquake. Even when wind and earthquake are acted on 
TABLE 7: Moment stress under the action of wind.

\begin{tabular}{lccccc}
\hline $\begin{array}{l}\text { Ground } \\
\text { elevation }(\mathrm{m})\end{array}$ & $\begin{array}{c}\text { Moment standard } \\
\text { value }(\mathrm{kN} \cdot \mathrm{m})\end{array}$ & $\begin{array}{c}\text { Bending section } \\
\text { coefficient }\left(\mathrm{m}^{3}\right)\end{array}$ & $\begin{array}{c}\text { Maximum } \\
\text { stress }(\mathrm{kPa})\end{array}$ & $\begin{array}{c}\text { Allowable bending and } \\
\text { eccentric compression }(\mathrm{kPa})\end{array}$ & $\begin{array}{c}\text { Allowable bending } \\
\text { tensile stress }(\mathrm{kPa})\end{array}$ \\
\hline 70 & 29.09 & 3.26 & 8.912 & 16700 & 16700 \\
65 & 116.34 & 3.54 & 32.82 & 16700 & 1570 \\
60 & 261.51 & 5.11 & 51.21 & 16700 & 1570 \\
55 & 463.86 & 4.96 & 93.45 & 16700 & 16700 \\
50 & 722.27 & 5.35 & 134.91 & 16700 & 1570 \\
45 & 1035.31 & 5.76 & 179.78 & 16700 & 1570 \\
40 & 1401.25 & 6.18 & 226.78 & 16700 & 1570 \\
35 & 1817.90 & 6.57 & 276.87 & 16700 & 1570 \\
30 & 2282.59 & 6.39 & 357.34 & 16700 & 1570 \\
25 & 2792.18 & 6.87 & 406.14 & 16700 & 1570 \\
20 & 3343.33 & 7.38 & 453.00 & 16700 & 1570 \\
0 & 4554.05 & 8.45 & 539.16 & 614.81 & \\
\hline
\end{tabular}

Max: $8.792 \mathrm{MPa}$

Min: $0.0032 \mathrm{MPa}$

$\begin{array}{llllllllllllll}0.60 & 1.20 & 1.80 & 2.40 & 3.00 & 3.60 & 4.20 & 4.80 & 5.40 & 6.00 & 6.60 & 7.20 & 7.80 & 8.40\end{array}$

Figure 6: Equivalent stress diagram of chimney at $6.02 \mathrm{~s}$.

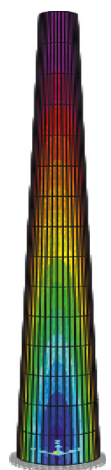

Max: $8.718 \mathrm{MPa}$

Min: $0.041 \mathrm{MPa}$

$\begin{array}{llllllllllllll}0.60 & 1.20 & 1.80 & 2.40 & 3.00 & 3.60 & 4.20 & 4.80 & 5.40 & 6.00 & 6.60 & 7.20 & 7.80 & 8.40\end{array}$

FIGURE 7: Equivalent stress diagram of a chimney at $6.00 \mathrm{~s}$.

the chimney, the amplitude does not exceed displacement limit in the code. Compared with linear elastic analysis, the nonlinear elastic analysis results, that are displacement and acceleration amplitudes, are slightly bigger except the displacement under wind action.

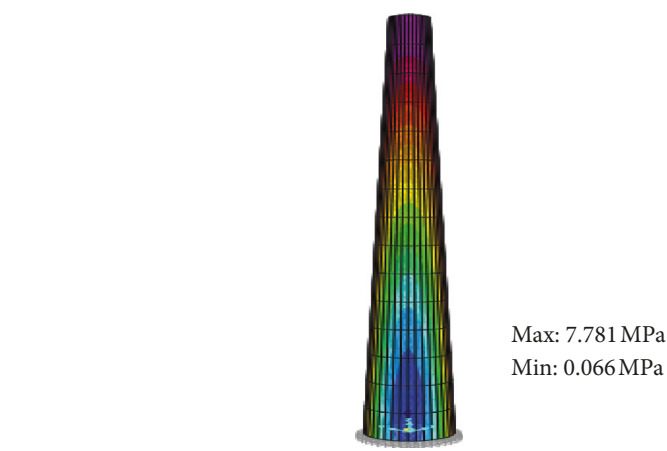

$\begin{array}{llllllllllllll}0.55 & 1.10 & 1.65 & 2.20 & 2.75 & 3.30 & 3.85 & 4.40 & 4.95 & 5.50 & 6.05 & 6.60 & 7.15 & 7.70\end{array}$

Figure 8: Equivalent stress diagram of a chimney at $5.96 \mathrm{~s}$.

\subsection{Security Assessment}

(1) Displacement Evaluation. A large number of relevant studies show that RC displacement does not exceed displacement limit $\mathrm{H} / 100$ under wind load alone. The maximum displacement of an RC chimney at $75 \mathrm{~m}$ under earthquake action alone meets the displacement limit.

(2) Stress Assessment. Under frequent earthquake action alone, the maximum compressive stress at the bottom of the chimney is $-1311.37 \mathrm{kPa}$, and the maximum tensile stress is $1205.30 \mathrm{kPa}$. Under wind load action alone, the maximum value of the bending moment is $614.81 \mathrm{kPa}$. Under rare earthquake action alone, the maximum compressive stress at the bottom of the chimney is $1865.22 \mathrm{kPa}$, and maximum tensile stress is $1607.95 \mathrm{kPa}$. Under the combined action of earthquakes and wind load, the maximum compressive stress at the bottom of the chimney is $-3569.22 \mathrm{kPa}$, and the maximum tensile stress is $695.1634 \mathrm{kPa}$.

In summary, the displacement of the RC chimney meets the specification under the action of wind load or earthquake, and the ultimate bearing capacity of the RC chimney also meets the design requirements (excluding rare earthquake). Therefore, some reinforcement measures should be taken to ensure safety. Through the calculation of structural 
TABLE 8: Maximum stress values under the action of a horizontal earthquake.

\begin{tabular}{|c|c|c|c|c|c|c|}
\hline $\begin{array}{l}\text { Ground } \\
\text { elevation (m) }\end{array}$ & $\begin{array}{l}\text { Moment standard } \\
\text { value }(\mathrm{kN} \cdot \mathrm{m})\end{array}$ & $\begin{array}{l}\text { Bend section } \\
\text { coefficient }\left(\mathrm{m}^{3}\right)\end{array}$ & $\begin{array}{c}\text { Maximum } \\
\text { compressive stress } \\
(\mathrm{kPa})\end{array}$ & $\begin{array}{l}\text { Maximum tensile } \\
\text { stress }(\mathrm{kPa})\end{array}$ & $\begin{array}{c}\text { Compression } \\
\text { design value }(\mathrm{kPa})\end{array}$ & $\begin{array}{c}\text { Tensile design } \\
\text { value }(\mathrm{kPa})\end{array}$ \\
\hline 75 & - & 2.99 & - & - & 16700 & 1570 \\
\hline 70 & 219.33 & 3.26 & -180.35 & 45.97 & 16700 & 1570 \\
\hline 65 & 700.45 & 3.54 & -310.76 & 84.49 & 16700 & 1570 \\
\hline 60 & 1309.03 & 5.11 & -353.44 & 159.28 & 16700 & 1570 \\
\hline 55 & 1968.79 & 4.96 & -510.24 & 283.04 & 16700 & 1570 \\
\hline 50 & 2634.99 & 5.35 & -605.75 & 378.60 & 16700 & 1570 \\
\hline 45 & 3295.78 & 5.76 & -685.85 & 458.74 & 16700 & 1570 \\
\hline 40 & 3962.04 & 6.18 & -751.47 & 530.96 & 16700 & 1570 \\
\hline 35 & 4651.01 & 6.57 & -814.32 & 602.42 & 16700 & 1570 \\
\hline 30 & 5372.64 & 6.39 & -962.02 & 720.16 & 16700 & 1570 \\
\hline 25 & 6144.52 & 6.87 & -1014.42 & 773.10 & 16700 & 1570 \\
\hline 20 & 6995.77 & 7.38 & -1131.34 & 764.42 & 16700 & 1570 \\
\hline 10 & 9050.11 & 8.45 & -1205.30 & 831.54 & 16700 & 1570 \\
\hline 0 & 11554.05 & 9.59 & -1311.37 & 1205.30 & 16700 & 1570 \\
\hline
\end{tabular}

TABle 9: Maximum shear stress under the action of a horizontal earthquake.

\begin{tabular}{lccc}
\hline $\begin{array}{l}\text { Ground elevation } \\
(\mathrm{m})\end{array}$ & $\begin{array}{c}\text { Shear standard value } \\
(\mathrm{kN})\end{array}$ & $\begin{array}{c}\text { Maximum stress at bottom of different section } \\
(\mathrm{kPa})\end{array}$ & $\begin{array}{c}\text { Design value of shear capacity } \\
(\mathrm{kPa})\end{array}$ \\
\hline 75 & - & 0 & 1099 \\
70 & 43.87 & 22.20 & 1099 \\
65 & 96.87 & 47.11 & 1099 \\
60 & 124.36 & 44.14 & 1099 \\
55 & 138.82 & 49.95 & 1099 \\
50 & 147.41 & 51.14 & 1099 \\
45 & 155.88 & 52.21 & 1099 \\
40 & 166.69 & 53.97 & 1099 \\
35 & 177.07 & 49.80 & 1099 \\
30 & 189.28 & 53.94 & 1099 \\
25 & 207.86 & 57.18 & 1099 \\
20 & 231.65 & 61.59 & 1099 \\
10 & 273.83 & 68.23 & 1099 \\
0 & 306.22 & 71.79 & 1099 \\
\hline
\end{tabular}

displacement and internal force under the combined action of wind and earthquake, it is concluded that the internal force and the displacement of the chimney can meet the design requirements in this case.

\section{Conclusions}

Based on the linear filtering method, the wind load of several heights on one field is simulated by MATLAB, the displacement of the structure under the action of wind load and earthquake is analyzed, and the stresses of the chimney in three cases are calculated. The main conclusions are as follows:

(1) With the increase of chimney height, the time at which the extreme value of displacement occurs consistently decreases. The extreme displacement value of an RC chimney meets the requirements under wind or earthquake, and the displacement also meets the specified limit under the combined action of wind and earthquake. According to the calculated results, the response of the structure under wind load is very obvious, and because wind load lasts for a long time, the vibration cycle of the structure itself lengthens. Under this condition, although the displacement of the apex of the structure reaches almost 130 millimeters, the equivalent stress at the time of the extreme displacement value satisfies the requirement of the carrying capacity because of its material properties. Because the chimney construction time is long, after a long period of vibration, the chimney may experience security risks.

(2) The extreme value of stress develops progressively from the bottom of the structure to the top of the structure over time. The bearing capacity of the RC chimney meets the design requirements under wind load or earthquake action alone. However, a partial tensile failure at the bottom of the chimney may occur during rare earthquakes. Therefore, we should take reinforcement measures to ensure safety. By calculating the internal force of the structure under the combined response to wind load and 
TABLE 10: Maximum stress values under the action of a rare earthquake.

\begin{tabular}{|c|c|c|c|c|c|c|c|c|}
\hline $\begin{array}{l}\text { Ground } \\
\text { elevation } \\
(\mathrm{m})\end{array}$ & $\begin{array}{l}\text { Standard } \\
\text { value } \\
(\mathrm{kN} \cdot \mathrm{m})\end{array}$ & $\begin{array}{l}\text { Bending } \\
\text { section } \\
\text { coefficient } \\
\left(\mathrm{m}^{3}\right)\end{array}$ & $\begin{array}{l}\text { Representative } \\
\text { value of gravity } \\
\text { load }(\mathrm{kN})\end{array}$ & $\begin{array}{l}\text { Sectional } \\
\text { area }\left(\mathrm{m}^{2}\right)\end{array}$ & $\begin{array}{l}\text { Maximum } \\
\text { compressive } \\
\text { stress }(\mathrm{kPa})\end{array}$ & $\begin{array}{l}\text { Maximum } \\
\text { tensile } \\
\text { stress } \\
(\mathrm{kPa})\end{array}$ & $\begin{array}{c}\text { Allowable compression } \\
\text { and } \\
\text { eccentric } \\
\text { compression }(\mathrm{kPa})\end{array}$ & $\begin{array}{l}\text { Allowable } \\
\text { stress } \\
\text { value } \\
(\mathrm{kPa})\end{array}$ \\
\hline 75 & - & 2.995744 & - & 3.79155 & - & - & 16700 & 1570 \\
\hline 70 & 290.3 & 3.264231 & 242.1 & 3.952004 & -263.53 & 68.96 & 16700 & 1570 \\
\hline 65 & 990.8 & 3.5444 & 735.3 & 4.112458 & -353.14 & 126.74 & 16700 & 1570 \\
\hline 60 & 1863.2 & 5.106243 & 1248.5 & 5.635044 & -530.16 & 238.92 & 16700 & 1570 \\
\hline 55 & 2953.2 & 4.963714 & 1867.5 & 5.558742 & -665.36 & 424.56 & 16700 & 1570 \\
\hline 50 & 3952.5 & 5.353799 & 2564.4 & 5.76504 & -808.63 & 567.90 & 16700 & 1570 \\
\hline 45 & 4943.7 & 5.758896 & 3287.0 & 5.971338 & -928.82 & 688.11 & 16700 & 1570 \\
\hline 40 & 5963.1 & 6.179006 & 4035.4 & 6.177636 & -1127.45 & 796.44 & 16700 & 1570 \\
\hline 35 & 6976.5 & 6.565771 & 4809.5 & 7.111786 & -1241.48 & 903.63 & 16700 & 1570 \\
\hline 30 & 8058.9 & 6.387701 & 5664.0 & 7.018528 & -1343.26 & 1080.24 & 16700 & 1570 \\
\hline 25 & 9216.8 & 6.874921 & 6601.1 & 7.27067 & -1421.87 & 1259.65 & 16700 & 1570 \\
\hline 20 & 10595.9 & 7.380467 & 7569.6 & 7.522812 & -1567.06 & 1346.63 & 16700 & 1570 \\
\hline 10 & 13575.5 & 8.446556 & 9152.3 & 8.027096 & -1667.05 & 1447.31 & 16700 & 1570 \\
\hline 0 & 17031.2 & 9.586003 & 11278.6 & 8.53138 & -1865.22 & 1607.95 & 16700 & 1570 \\
\hline
\end{tabular}

TABLe 11: Maximum stress values under the action of earthquakes and wind.

\begin{tabular}{|c|c|c|c|c|c|c|c|c|}
\hline $\begin{array}{l}\text { Ground } \\
\text { elevation } \\
(\mathrm{m})\end{array}$ & $\begin{array}{l}\text { Standard } \\
\text { value } \\
(\mathrm{kN} \cdot \mathrm{m})\end{array}$ & $\begin{array}{l}\text { Bending } \\
\text { section } \\
\text { coefficient } \\
\left(\mathrm{m}^{3}\right)\end{array}$ & $\begin{array}{l}\text { Representative } \\
\text { value of gravity } \\
\text { load }(\mathrm{kN})\end{array}$ & $\begin{array}{l}\text { Sectional } \\
\text { area }\left(\mathrm{m}^{2}\right)\end{array}$ & $\begin{array}{l}\text { Maximum } \\
\text { compressive } \\
\text { stress }(\mathrm{kPa})\end{array}$ & $\begin{array}{l}\text { Maximum } \\
\text { tensile stress } \\
(\mathrm{kPa})\end{array}$ & $\begin{array}{l}\text { Allowable compression } \\
\text { and } \\
\text { eccentric compression } \\
(\mathrm{kPa})\end{array}$ & $\begin{array}{c}\text { Allowable } \\
\text { stress } \\
\text { value } \\
(\mathrm{kPa})\end{array}$ \\
\hline 75 & - & 2.995744 & - & 3.79155 & - & - & 16700 & 1570 \\
\hline 70 & 315.5 & 3.264231 & 242.1 & 3.952004 & -163.243 & 30.06401 & 16700 & 1570 \\
\hline 65 & 1031.8 & 3.5444 & 735.3 & 4.112458 & -485.461 & 96.75348 & 16700 & 1570 \\
\hline 60 & 1973.2 & 5.106243 & 1248.5 & 5.635044 & -627.265 & 145.5933 & 16700 & 1570 \\
\hline 55 & 3038.5 & 4.963714 & 1867.5 & 5.558742 & -977.328 & 246.9568 & 16700 & 1570 \\
\hline 50 & 4167.4 & 5.353799 & 2564.4 & 5.76504 & -1261.92 & 294.8822 & 16700 & 1570 \\
\hline 45 & 5341.3 & 5.758896 & 3287.0 & 5.971338 & -1525.84 & 329.1336 & 16700 & 1570 \\
\hline 40 & 6570.7 & 6.179006 & 4035.4 & 6.177636 & -1773.45 & 353.3331 & 16700 & 1570 \\
\hline 35 & 7873.8 & 6.565771 & 4809.5 & 7.111786 & -1934.33 & 464.112 & 16700 & 1570 \\
\hline 30 & 9258.5 & 6.387701 & 5664.0 & 7.018528 & -2326.64 & 572.2096 & 16700 & 1570 \\
\hline 25 & 10741.9 & 6.874921 & 6601.1 & 7.27067 & -2549.37 & 575.5801 & 16700 & 1570 \\
\hline 20 & 12355.9 & 7.380467 & 7569.6 & 7.522812 & -2767.9 & 580.3747 & 16700 & 1570 \\
\hline 10 & 16094.5 & 8.446556 & 9152.3 & 8.027096 & -3144.82 & 666.0802 & 16700 & 1570 \\
\hline 0 & 20439.2 & 9.586003 & 11278.6 & 8.53138 & -3569.22 & 695.1634 & 16700 & 1570 \\
\hline
\end{tabular}

TABLE 12: The displacement and acceleration amplitudes considering materials' nonlinearity and $P-\Delta$ effect.

\begin{tabular}{|c|c|c|c|c|}
\hline Groun & elevation (m) & 25 & 50 & 75 \\
\hline \multirow{2}{*}{ Wind load } & $\begin{array}{l}\text { Displacement amplitude } \\
(\mathrm{mm})\end{array}$ & 15 & 60 & 127 \\
\hline & $\begin{array}{l}\text { Acceleration amplitude } \\
\left(\mathrm{m} / \mathrm{s}^{2}\right)\end{array}$ & 1.11 & 2.74 & 5.83 \\
\hline \multirow{2}{*}{ Earthquake } & $\begin{array}{l}\text { Displacement amplitude } \\
\qquad(\mathrm{mm})\end{array}$ & 61 & 239 & 498 \\
\hline & $\begin{array}{l}\text { Acceleration amplitude } \\
\qquad\left(\mathrm{m} / \mathrm{s}^{2}\right)\end{array}$ & 7.86 & 9.54 & 26.4 \\
\hline \multirow{2}{*}{$\begin{array}{l}\text { Wind load and } \\
\text { earthquake }\end{array}$} & $\begin{array}{l}\text { Displacement amplitude } \\
\qquad(\mathrm{mm})\end{array}$ & 69 & 318 & 550 \\
\hline & $\begin{array}{l}\text { Acceleration amplitude } \\
\qquad\left(\mathrm{m} / \mathrm{s}^{2}\right)\end{array}$ & 8.9 & 11.4 & 24.8 \\
\hline
\end{tabular}

earthquakes, the internal force meets the design requirements, and the effect on the displacement response is greatly influenced by the effect of the structure. By comparing the combined response with the stress response, it can be determined that the combined response has a greater impact on the displacement of the structure.

(3) It is not scientific or authentic to determine the safety performance of the structure based only on the displacement from the value of maximum tensile stress under rare earthquake conditions. Additionally, the weak spots of the structure indicate that the bottom may experience partial tensile failure, and the displacement at the upper apex may not meet the specified limit. The displacement and stress should be used as the basis for the safety evaluation of the 
RC chimney in future structure design, detection, and reinforcement.

(4) For the results of wind load and earthquake together, the extreme displacement values satisfy the displacement limits at the top of the chimney, but the extreme stress is too large, which is consistent with the location of chimney rupture and crack. Thus, the calculation is true and effective, and there are some hidden dangers in the chimney under the combined action of earthquake and wind load, and the safety performance is unreliable. Therefore, it is necessary to consider both wind load and earthquake interaction in future chimney design.

\section{Data Availability}

The data used to support the findings of this study are available from the corresponding author upon request.

\section{Conflicts of Interest}

The authors declare that there are no conflicts of interest regarding the publication of this paper.

\section{Acknowledgments}

This paper is part of the project of the National Natural Science Foundation of China (Grant no. 51478212) and part of the Science and Technology Project of the China Railway 12th Bureau Group (Grant no. 14B-3).

\section{References}

[1] J. Liu and L. M. He, "Analysis of seismic response of chimneys to combined horizontal and vertical ground motion," Earthquake Engineering and Engineering Vibration, vol. 2, pp. 89-98, 1983.

[2] S. J. Pan and Z. M. Xu, "Seismic response analysis of R.C.TV towers and chimneys," China Civil Engineering Journal, vol. 16, no. 2, pp. 89-98, 1983.

[3] H. W. Ma and D. D. Zhang, "Seismic response of a prestressed concrete wind turbine tower," International Journal of Civil Engineering, vol. 14, no. 8, pp. 561-571, 2016.

[4] M. P. Rashmi and D. S. Sandeep Kumar, "Seismic performance study on RC chimney," International Research Journal of Engineering and Technology, vol. 4, no. 6, pp. 2920-2925, 2017.

[5] J. Liu, L. M. He, and S. H. She, "Research on vertical seismic action of structures," Journal of Harbin University of Civil Engineering and Architecture, vol. 2, pp. 14-27, 1986.

[6] A. J. Chen and Y. H. Ren, "Seismic response analysis for chimney based on finite element analysis software," Journal of Water Resources and Architectural Engineering, vol. 8, no. 3, pp. 129-131, 2010.

[7] Q. Liu, R. Z. Zhou, and W. J. Yuan, "Computation of earthquake transient response of skyscraper structures and study of the dynamic properties," China Civil Engineering Journal, vol. 43, no. 5, pp. 63-69, 2010.

[8] L. Shiau and H. T. Y. Yang, "Elastic-Plastic seismic response of chimney," Journal of the Structural Division, vol. 106, no. 4, pp. 791-807, 1980.
[9] J. L. Wilson, Earthquake Design and Analysis of Tall Reinforced Concrete Chimneys, The University of Melbourne, Melbourne, Australia, 2000.

[10] J. L. Wilson, "Earthquake response of tall reinforced concrete chimneys," Engineering Structures, vol. 25, no. 1, pp. 11-24, 2003.

[11] Q. S. Li, L. H. Zhi, Y. Alex, and C. S. Kao, "Dynamic behavior of Taipei 101 tower: field measurement and numerical analysis," Journal of Structural Engineering, vol. 137, no. 1, pp. 143-155, 2011.

[12] R. Q. Feng, G. R. Yan, and J. M. Ge, "Effects of high modes on the wind-induced response of super high-rise buildings," Earthquake Engineering \& Engineering Vibration, vol. 11, no. 3, pp. 427-434, 2012.

[13] L. L. Li and L. Y. Lu, "Identification of the tall structure wind load based on pseudo-excitation method," Construction and Design For Project, vol. 4, pp. 72-75, 2012.

[14] Y. Li and Q. S. Li, "Wind-induced response based equivalent static wind load optimum design for tall building," Journal of Hunan University (Natural Science), vol. 40, no. 4, p. 26, 2013.

[15] F. Minghini, G. Milani, and A. Tralli, "Seismic risk assessment of a $50 \mathrm{~m}$ high masonry chimney using advanced analysis techniques," Engineering Structures, vol. 69, no. 15, pp. 255270, 2014.

[16] F. Yang, D. P. Lv, H. Cao, Y. F. Zhou, and Y. R. Wu, "The appraisal example of the reliability and seismic performance of a reinforced concrete chimney," Applied Mechanics and Materials, vol. 204-208, pp. 2399-2404, 2012.

[17] A. C. Altunisik, "Comparison of earthquake behavior of reinforced concrete minarets using fiber-reinforced polymer composite," The Structural Design of Tall and Special Buildings, vol. 22, no. 9, pp. 749-758, 2013.

[18] Z. Karaca, E. Türkeli, M. Günaydın, and S. Adanur, "Dynamic responses of industrial reinforced concrete chimneys strengthened with fiber-reinforced polymers", "The Structural Design of Tall and Special Buildings, vol. 24, no. 3, pp. 228-241, 2015.

[19] C. D. Zhou, X. L. Zeng, Q. L. Pan, and B. Liu, "Seismic fragility assessment of a tall reinforced concrete chimney," The Structural Design of Tall and Special Buildings, vol. 24, no. 6, pp. $440-460,2015$.

[20] P. Gorski, "Some aspects of the dynamic cross-wind response of tall industrial chimney," Wind and Structures, vol. 12, no. 3 , pp. 259-279, 2009.

[21] A. L. Iban, J. M. W. Brownjohn, A. V. Belver, P. M. LopezReyes, and K. Koo, "Numerical modelling for evaluating the TMD performance in an industrial chimney," Wind and Structures, vol. 17, no. 3, pp. 263-274, 2013.

[22] Y. Cohen, A. Livshits, and R. Nascimbene, "Comparative approach to seismic vulnerability of an elevated steel tank within a reinforced concrete chimney," Periodica Polytechnica Civil Engineering, vol. 61, no. 3, p. 361, 2017.

[23] P. A. Bońkowski, Z. Zembaty, and M. Y. Minch, "Time history response analysis of a slender tower under translationalrocking seismic excitations," Engineering Structures, vol. 155, pp. 387-393, 2018.

[24] M. J. He and X. Li, "Performance-based anti-wind design for high-rise buildings," Journal of Vibration and Shock, vol. 32, no. 3, pp. 87-94, 2013.

[25] B. Yuan, H. Q. Ying, and J. W. Xu, "Simulation of turbulent wind velocity based on linear filter method and MATLAB program realization," Structural Engineers, vol. 23, no. 4, pp. 55-61, 2007. 
[26] J. Liang and D. F. Zhao, "Summary of the model analysis method," Modern Manufacturing Engineering, vol. 8, pp. 139-141, 2006.

[27] Y. H. Wu, Y. Yin, and L. Liu, "Reasonable mode number required in mode superposition response analysis for space frame structures," Spatial Structures, vol. 21, no. 4, pp. 25-31, 2015. 


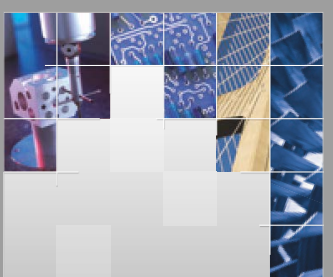

\section{Enfincering}
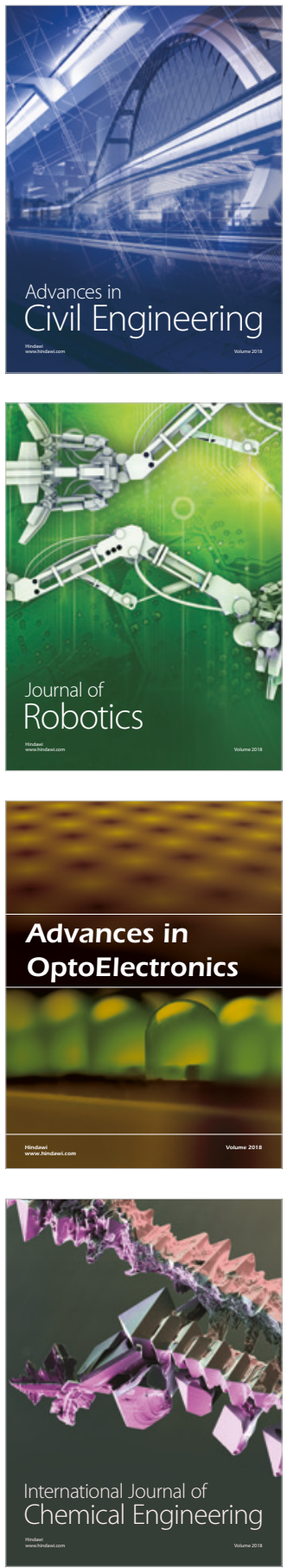

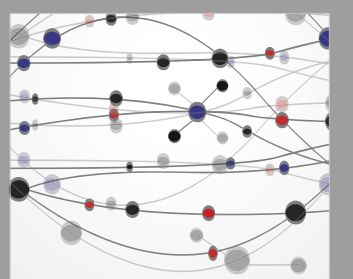

\section{Rotating \\ Machinery}

The Scientific World Journal

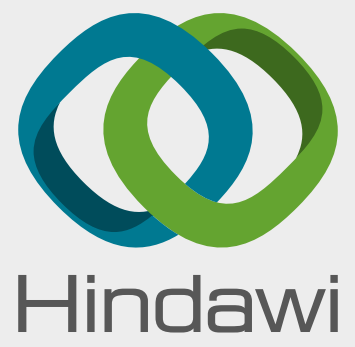

Submit your manuscripts at

www.hindawi.com
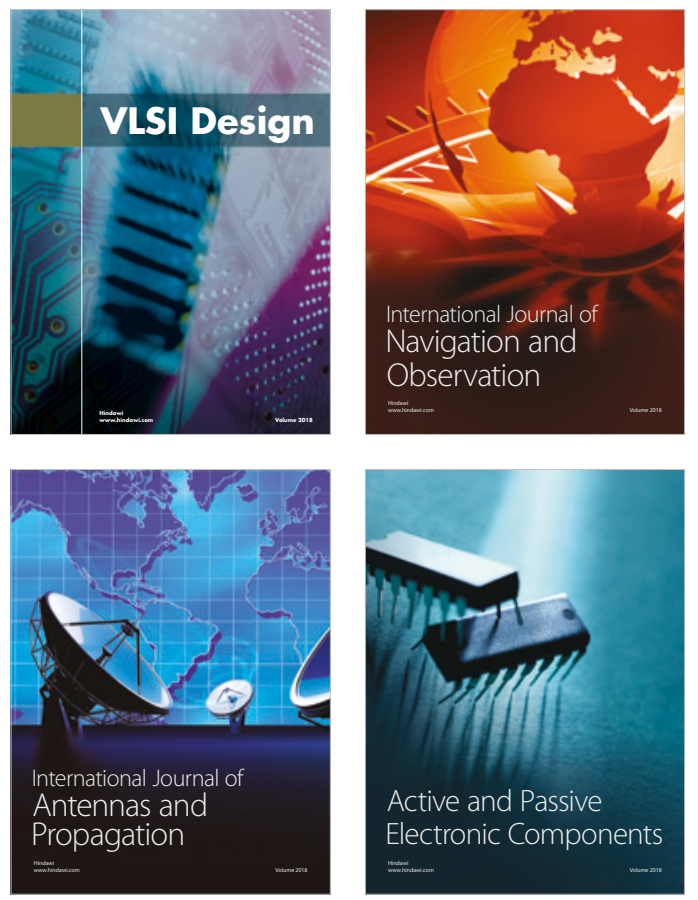
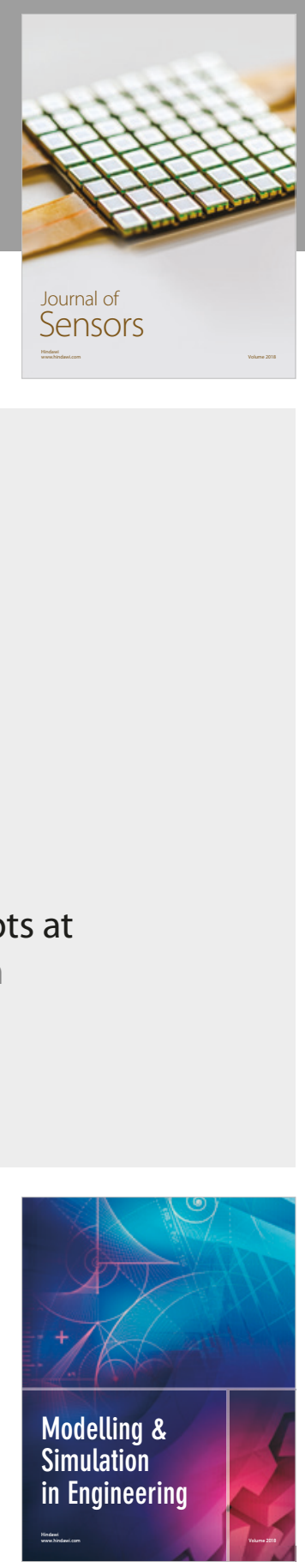

\section{Advances \\ Multimedia}
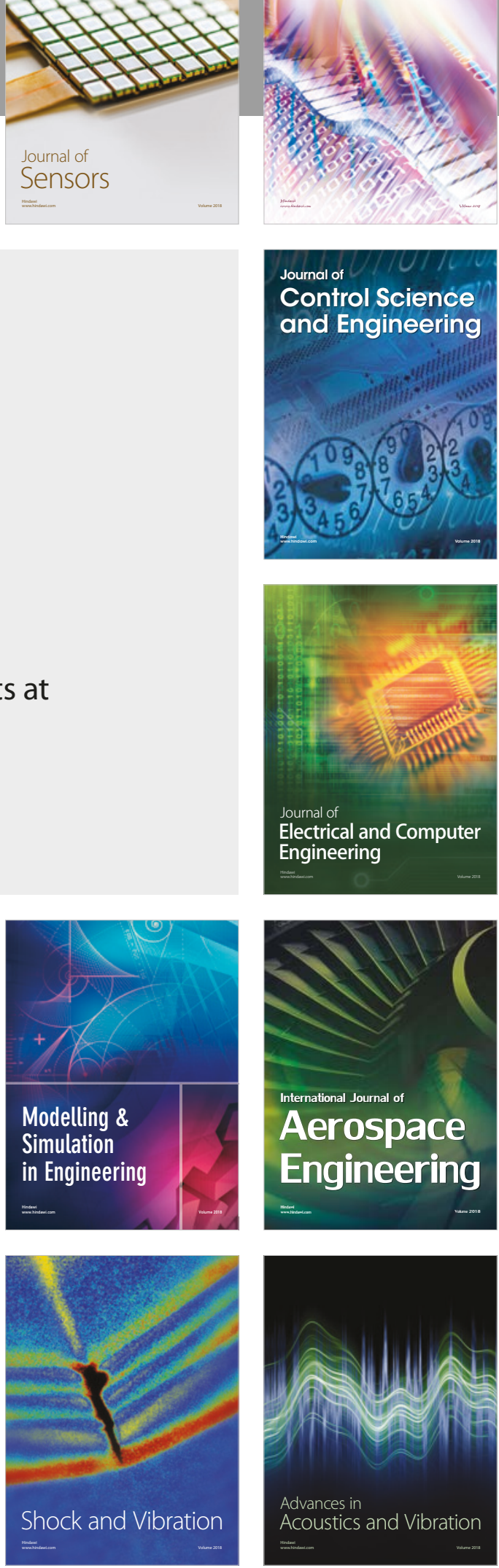